\title{
Numerical modeling of the microclimate and air quality of an Orthodox church in Saint- Petersburg
}

\author{
Inna Sukhanova ${ }^{1, *}$ \\ ${ }^{1}$ Saint-Petersburg State University of Architecture and Civil Engineering, 2-nd Krasnoarmeiskaya st. \\ 4, 190005 St. Petersburg, Russia
}

\begin{abstract}
A numerical model of the microclimate and air quality in the premises of an Orthodox church is built in STAR CCM+ software. The building of the Church of the Nativity with a capacity of 900 people in St. Petersburg was adopted for modeling. The model takes into account features of architecture, heating equipment, the number of people and candles. There is a warm floor in the prayer hall to compensate for the loss of heat. The supply of fresh air in the serviced area is provided by inclined falling jets, and the removal of air is provided through the transom. The distribution of velocity and temperature fields and concentrations of $\mathrm{CO}_{2}$ in the main premises of the church (vestibule, prayer hall, altar) was obtained under nonstationary operation and full capacity of the church. The conclusion was made about the provision of normalized microclimate parameters in the premises of the church with the adopted design solutions for heating and ventilation systems.
\end{abstract}

\section{Introduction}

Ventilation and air conditioning systems determine the state of the microclimate and air quality in the premises. The air quality in the premises of public buildings is ensured by the necessary level of ventilation (the amount of air exchange in the premises), which ensures the permissible values of carbon dioxide $\left(\mathrm{CO}_{2}\right)$ in the room [1].

At the design stage, for checking of the adopted design decisions and assessing the possibility of providing thermal comfort and air quality, numerical modeling methods are used. This is especially necessary for complex, atypical buildings [2-13].

The buildings of Orthodox churches have architectural and operational features that complicate design solutions and do not allow assessing the state of the microclimate and air quality using traditional calculation methods $[2,3]$. It is necessary to take into account the conditions of the services, the presence of icons, frescoes, art paintings, and other interior items, which are often of historical and artistic value [8].

The temperature of the internal air in the prayer room in the cold period of the year should be $14-16^{\circ} \mathrm{C}$. During service on the days of the patronal holidays, the number of people in the hall often exceeds the design value, and the rest of the time, the capacity of halls is much

\footnotetext{
*Corresponding author: Inna.suhanova@mail.ru
} 
lower. In addition, services are always accompanied by lit candles, the combustion products of which also affect the temperature and air quality. Therefore, it is necessary to conduct scientific studies that take into account the dynamics of the heat and humidity regime in the premises of churches, allowing to identify patterns of microclimate formation with a different number of people in the building [7].

\section{Materials and Methods}

The task is to study the microclimate parameters and the internal air quality in the main premises of an Orthodox church located in St. Petersburg and to obtain the distribution of temperature and velocity fields and $\mathrm{CO} 2$ concen trations in these premises.

The research tool in this paper is STAR-CCM+ hydrodynamic computing complex [4$6,9,10,13]$. This program allows obtaining the distribution of temperature and velocity fields in the premises to assess the microclimate and air quality in the served area.

The building of the Church of the Nativity with a capacity of 900 people in St. Petersburg is taken as a model. The main premises of the church, namely the vestibule, the prayer hall, and the altar, are considered in detail, since it is in these premises where the bulk of the people who come to the service are located. 3].

Heating and ventilation systems are designed in accordance with the requirements of [1-

Estimated outdoor temperature is $-24{ }^{\circ} \mathrm{C}$. The design temperature of the internal air is + $14{ }^{\circ} \mathrm{C}$. The heat losses of the considered rooms are equal to $82668 \mathrm{~W}$, including $13778 \mathrm{~W}$ the heat flux to the heating of the infiltrating outside air.

To compensate for the loss of heat in the prayer room, a warm floor is provided, in the confessionals - a warm floor and radiators, in the remaining rooms - radiator heating system. In the vestibule of the church, the installation of air-heat curtains is provided.

The intake air is supplied to the served area by inclined falling jets through wall mounted air distributors located on the inner walls of the building at around $2.3 \mathrm{~m}$. Air removal from the main premises of the church is provided through transom in the large and small drums.

A three-dimensional model of the building was built (Fig. 1), taking into account the architectural features of the church, the location of the ejector grilles and heating equipment, candles and parishioners (900 people).

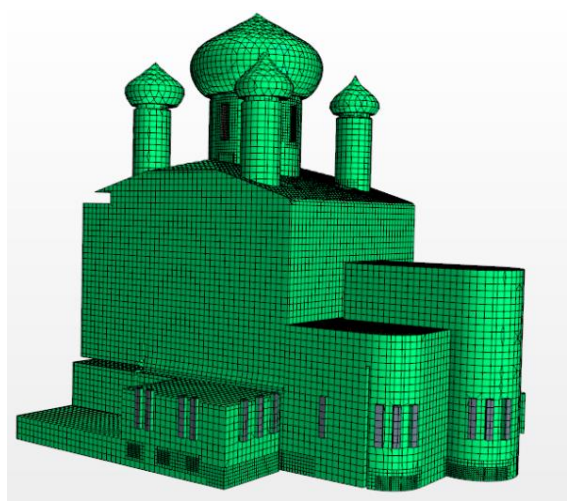

Fig. 1. The analysis grid of the building.

To get closer to the actual conditions of the service, the modeling of non-stationary processes in the room is performed (people gradually come to the church, then they stay inside for a long time, then gradually leave the church after the end of the service). 


\section{Results}

The results of calculations of velocity and temperature fields, the concentration of $\mathrm{CO}_{2}$ in the premises of the church with its maximum capacity are shown in Fig. 2 - 4.
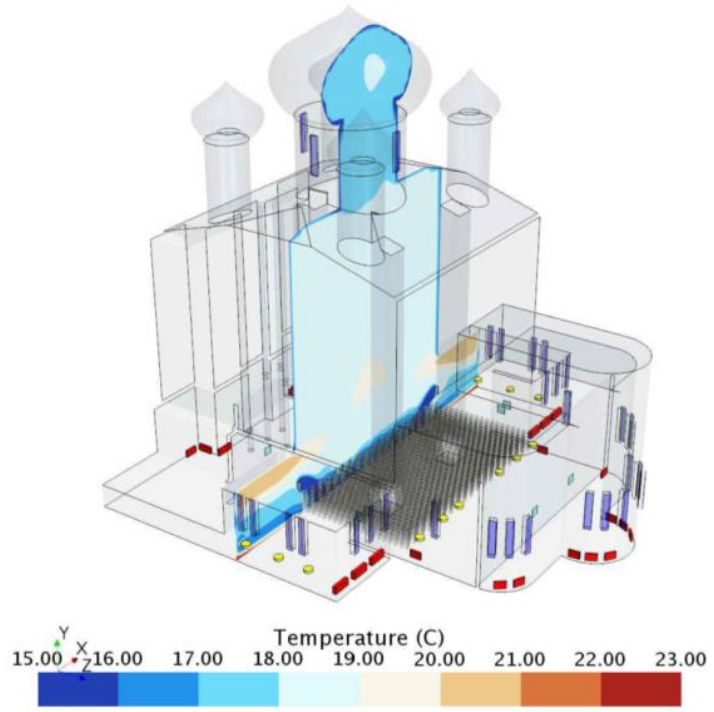

Fig. 2. The temperature field in the vertical section of the church.

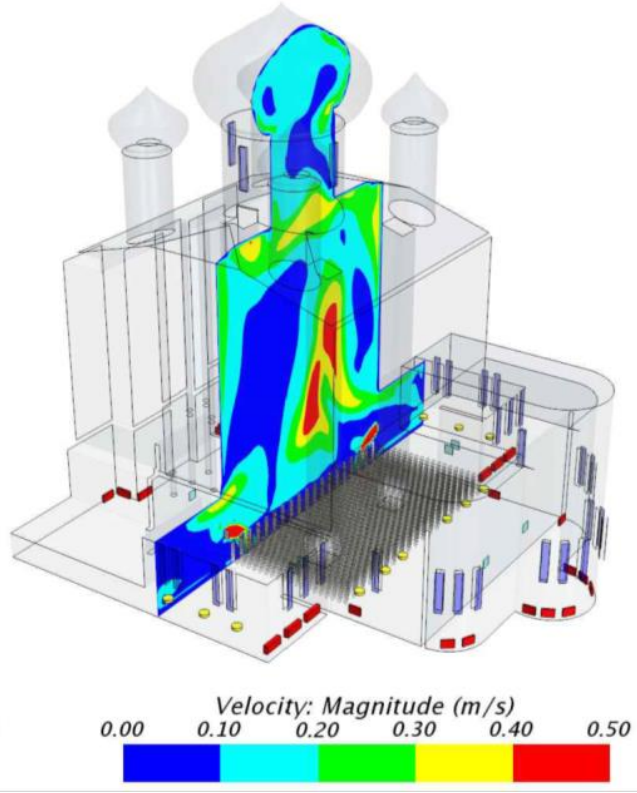

Fig. 3. The velocity field in the vertical section of the church. 


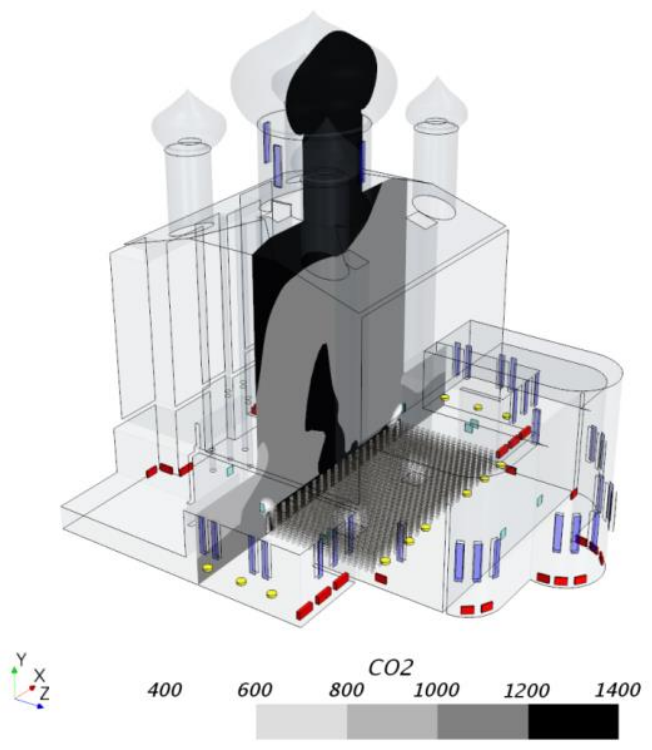

Fig. 4. The $\mathrm{CO}_{2}$ concentration field in the vertical section of the church.

As a result of the study of the dynamic model, the values of temperatures and $\mathrm{CO} 2$ concentrations in the serviced zone were obtained as the parishioners came and left, which are shown in Fig. 5 and 6. For the premises in question, the space in the room bounded by planes parallel to the floor and walls is taken as the serviced zone: at a height of 0.1 and $2 \mathrm{~m}$ above the floor level and at a distance of $0.5 \mathrm{~m}$ from the inner surfaces of the outer and inner walls, windows, and heating devices, and also from the candlesticks with burning candles in the prayer hall.

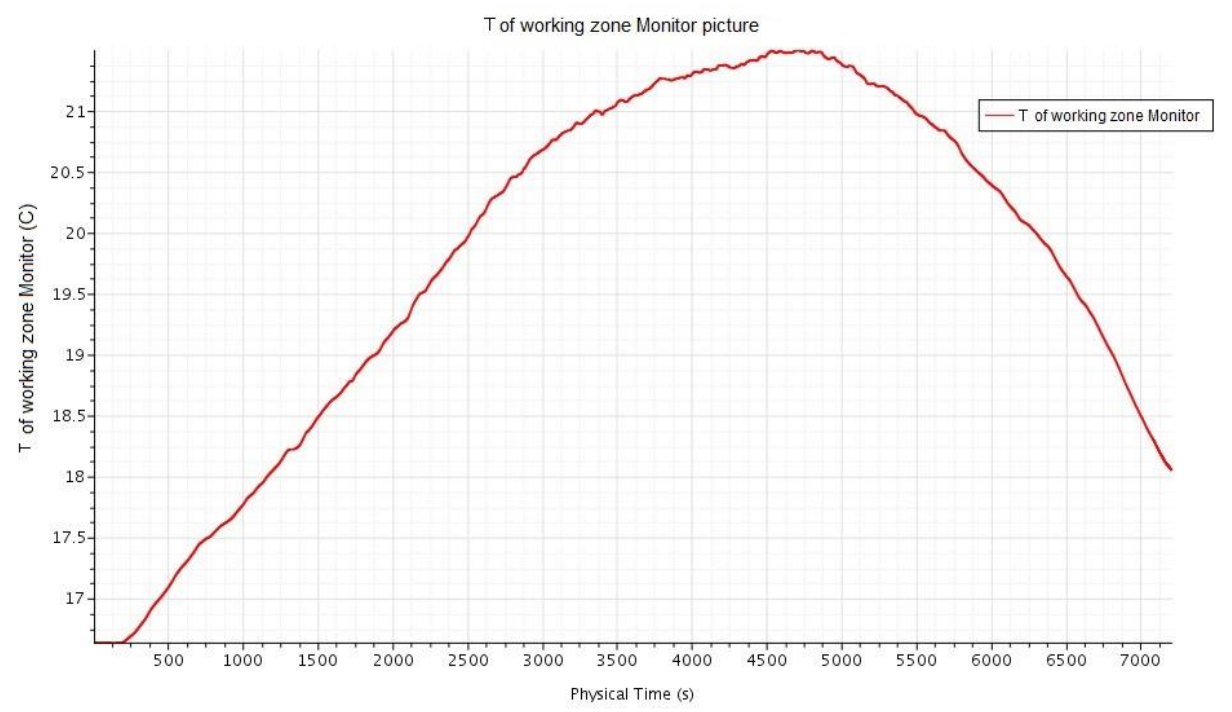

Fig. 5. Temperature dependency in the serviced zone during the coming and going of 900 parishioners. 


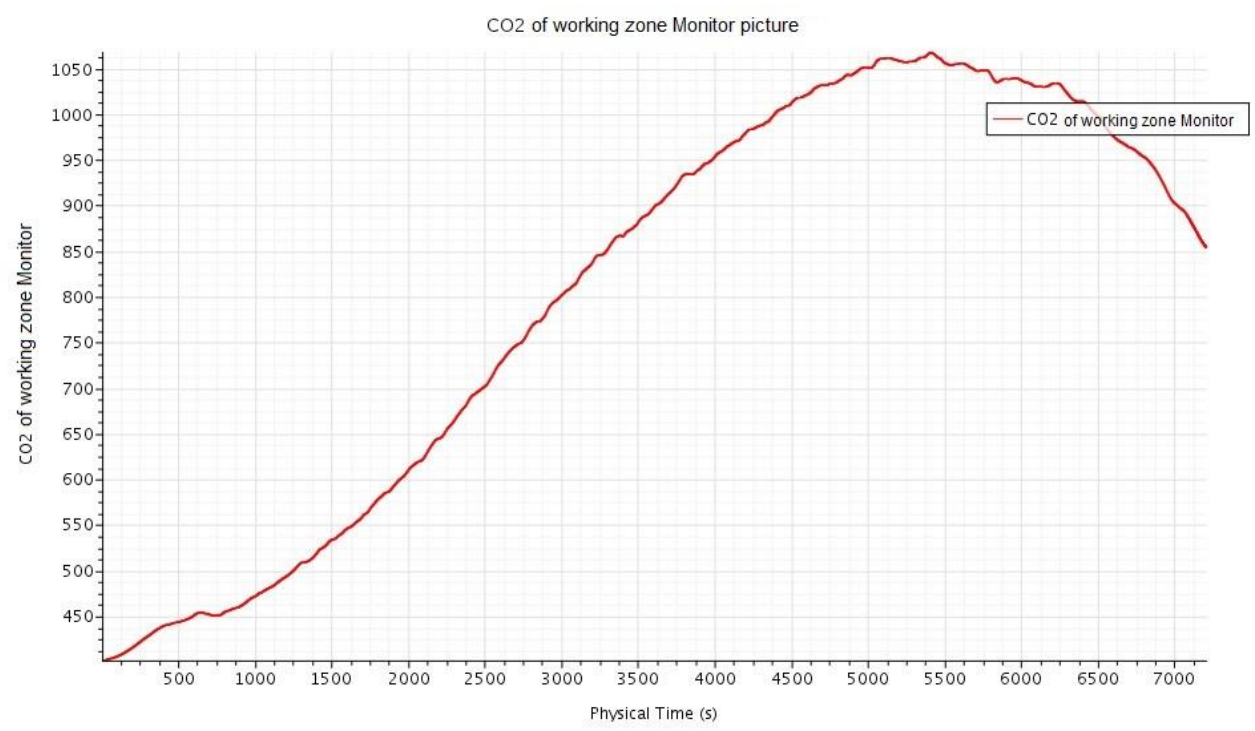

Fig. 6. Dependence of $\mathrm{CO}_{2}$ concentration in the serviced zone during the coming and going of 900 parishioners.

In the resulting graph (Fig. 6), the values of $\mathrm{CO} 2$ concentration are presented in ppm. It should be noted that these results of calculating the concentrations take into account the value of $\mathrm{CO} 2$ concentration of the incoming air (400 ppm).

\section{Discussion}

The performed studies allow tracing the change in air temperature and $\mathrm{CO}_{2}$ concentration in the serviced area in the central part of the church. With the gradual filling of the room up to a maximum capacity of 900 people (the number of burning candles also increases proportionally), the air temperature increases from 14 to $21.5^{\circ} \mathrm{C}$, and the concentration of $\mathrm{CO}_{2}$ from 400 to $1050 \mathrm{ppm}$.

The air temperature exceeds the optimal values equal to $16{ }^{\circ} \mathrm{C}$ for the central part, but with a long stay in the room, the parishioners often take off outer clothing. And for a crowded room in which people are mostly standing without street clothes, the permissible air temperature is $21^{\circ} \mathrm{C}$. The air velocity in the service area does not exceed $0.2 \mathrm{~m} / \mathrm{s}$, i.e. it is permissible in any mode of operation of the building.

The air quality in the church remains permissible even with the maximum number of parishioners (allowable $\mathrm{CO}_{2}$ concentration is $1400 \mathrm{ppm}$, taking into account the $\mathrm{CO}_{2}$ content in the incoming air - $400 \mathrm{ppm}$ ).

The considered dynamic model assumes that the maximum number of people stays in a room only for 20 minutes. In fact, services sometimes last for several hours, and the number of parishioners can significantly exceed the number provided for in the project. To assess the air quality in this case, additional research is needed.

\section{Conclusions}

1. The parameters of the microclimate of the church premises depend on the number of people in them. At maximum load, the air temperature in the serviced area may exceed the permissible values. 
2. The concentration of $\mathrm{CO}_{2}$ in the central part of the church is permissible even at maximum load.

3. Low-temperature underfloor heating in the prayer hall with mechanical inlet and natural exhaust ventilation ensures the normalized microclimatic parameters (temperature and air velocity) in the serviced area of an Orthodox church during the cold season.

\section{References}

1. Russian Federation Standard GOST 30494-2011

2. Standard of Association of HVAC Engineers AVOK-2-2004. Orthodox churches. Heating, ventilation, air conditioning (AVOK-PRESS, Moscow, 2004)

3. Russian Federation Standard SP 31-103-99

4. A.M. Grimitlin, T.A. Datsyuk, D.M. Denisihina, Mathematical modeling in the design of ventilation and air conditioning (AVOK North-West, St. Petersburg,2005)

5. D.M. Denisihina, Yu.V. Ivanova, V.V. Mokrov, Engineering journal of Don 2 (2018)

6. D. Denisikhina, A. Kolosnitsin, M. Lukanina, High-tech buildings 3, 66-71 (2013)

7. G.V. Esaulov, AVOK 2 (2017)

8. A.G. Kochev, AVOK 8 (2009)

9. V.A. Pukhkal, K.O. Sukhanov, A.M. Grimitlin, Bulletin of civil engineers 6(59), 156162 (2016)

10. V.R. Taurit, N.A. Korableva Bulletin of civil engineers 3(62), 166-170 (2017)

11. E. Chui, G. Raithby, Numerical Heat Transfer 23(B), 269-288 (1993)

12. A. Ploskic, S. Holmberg, Building and Environment 45(5), 1123-1133 (2010)

13. K. Sukhanov, A. Smirnov, Advances in Intelligent Systems and Computing 692, 592597 (2017) 